\title{
Machine grinding as an alternative method for creating functional surfaces for controlling cell behaviour
}

\author{
Michael Irving ${ }^{1} \cdot$ Mark F. Murphy $^{1} \cdot$ Mike N. Morgan $^{1} \cdot$ Francis Lilley $^{1} \cdot$ Paul French $^{1}$. \\ David R. Burton ${ }^{1}$ • Peter Moran ${ }^{1}$
}

Received: 3 December 2015 / Accepted: 19 February 2016/Published online: 7 March 2016

(C) The Author(s) 2016. This article is published with open access at Springerlink.com

\begin{abstract}
There is extensive evidence to show that certain cellular behaviours including cell proliferation, migration and adhesion can be controlled by culturing cells on surfaces containing different micro-metre- and nanometre-scale features. This paper will introduce the use of machine grinding to generate surfaces with micro-sized features and their ability to affect cell behaviour. Results are presented which show that polyurethane castings of the ground surfaces can promote cell adhesion and migration. This study demonstrates the usefulness of surface grinding as a cost-effective method for generating functional surfaces for modifying cell behaviour.
\end{abstract}

Keywords Grinding · Micro-topography $\cdot$ Fibroblast cells · Cell adhesion $\cdot$ Cell migration

\section{Introduction}

Mammalian cells have evolved to interact with their physical environment, and this interaction is crucial for many important cellular behaviours including the following: migration, division, differentiation and proliferation. In vivo, cells depend on an interaction with a 3D scaffold known as the extracellular matrix $(\mathrm{ECM})$. It is thought that the organisation and mechanical compliance of the ECM is extremely important in helping to regulate the aforementioned cell behaviours. It has been acknowledged that growing cells in flat planar environments,

Mark F. Murphy

M.F.Murphy@ljmu.ac.uk

1 General Engineering Research Institute, Liverpool John Moores University, Byrom Street, Liverpool L3 3AF, UK as is the case for most cell culture vessels, does not accurately replicate their natural environment. As a consequence, there has been a significant research effort that has focussed on the development of cell substrates having both $2 \mathrm{D}$ and $3 \mathrm{D}$ features that mimic features of the ECM. This has largely been achieved through patterning materials to develop 'functional' or 'smart' surfaces that can be used to better control cellular responses in vitro.

Initial work in this area focussed on producing simple step features [3]. This has since evolved to see the design of a range of surface features including islands [7], pits [23], grooves [1] and pillars [11], all of which have been shown to have an effect on cell behaviour. Such design features have been incorporated into the development of biomedical implant technology. For example, dental implants have been modified to increase surface roughness to improve implant integration [18], whereas modifying breast implants and stents to provide a rough surface topography has been shown to promote the surface adhesive properties for different cell types [20, 24].

The main techniques used for developing functional cell substrates include laser patterning [23], photolithography [1] and polish finishing techniques [22]. These methods vary in both process time and cost and have been extensively employed to generate surfaces for cell control. One method that has seemingly been overlooked is the use of grinding to generate the pattern. When compared to other methods, grinding shows several benefits. For example, grinding offers a smaller potential feature size, due to it not being limited by resolution, or spot size as the case with photolithography [16] and laser processing [10], respectively. It is also a relatively simpler manufacturing process, not requiring a clean room as is the case with lithography [6]. Little research has been done on grinding micro-patterned surfaces for cell control. However, the use of similar technologies, such as diamond micro-engraving tools for surface patterning, has shown 
promise, for example through the growth of osteoblast cells on such manufactured surfaces [13]. Similarly, a combination of both macro- and micro-grooves, generated by a microengraving process, was found to promote the formation of extracellular matrix and cell alignment of both osteoblasts [13] and fibroblast cells [20].

This paper demonstrates the suitability of grinding technology as a method for micro-patterning stainless steel, which can then be used as a master die, to cast polymer substrates for manipulating fibroblast cell behaviours.

\section{Experimental setup}

\subsection{Material and equipment}

\subsubsection{Grinding of surfaces}

Stainless steel cylinders (grade 316, 18-mm diameter $\times 13$ $\mathrm{mm}$ height) were used for the surface patterning; a manual controlled Jones \& Shipman 540 surface grinder was used to pattern the surface. The grinding wheel (Norton-AS346J7V) had dimensions of $160-\mathrm{mm}$ diameter and 19-mm width. Peripheral wheel speed was set to $25 \mathrm{~m} / \mathrm{s}$. The wheel was dressed with a single-point diamond, applying two passes at $100 \mu \mathrm{m} / \mathrm{s}$ at the different depths 2, 4, 6 and $10 \mu \mathrm{m}$. To pattern the surface, a single pass of the freshly dressed wheel was made at $3000 \mu \mathrm{m} / \mathrm{s}$. This was done for each wheel dressing depth to produce four different patterned surfaces, M1, M2, M3 and M4, respectively. The depth of cut on the stainless steel moulds was dependent upon the wheel dressing depth. Increasing the dressing depth from 2 to $10 \mu \mathrm{m}$ resulted in a depth of cut ranging between in 2 and $5 \mu \mathrm{m}$.

\subsubsection{Casting of polymer substrates from stainless steel moulds}

Casting the polymer over the metal moulds produces an inverted pattern. The polyurethane was provided by Biomer Technology Ltd; the polymer substrates were produced using $8 \%$ polyurethane in 2:1 dimethylformamide (DMF) and tetrahydrofuran (THF). This was poured onto the metal moulds and cured at $60{ }^{\circ} \mathrm{C}$ for $2 \mathrm{~h}$.

\subsubsection{White light interferometry}

All white light images presented in this report were obtained using a Bruker Contour GT-K 3D optical microscope via Vision 64 software. This microscope is equipped with the following objective lens: $\times 2.5, \times 10$ and $\times 25$ and field-ofview multiplier lenses: $\times 0.55, \times 1.0$ and $\times 2.0$. Images were taken at either $\times 25$ or $\times 50$ magnification.

\subsection{Experimental procedure}

\subsubsection{Cell culture}

The cells described in this work are human lung fibroblast cells (LL24), which have been purchased from the European Collection of Animal Cell Cultures (ECACC). All cell culture work was carried out under aseptic conditions in a grade II laminar flow cabinet (EBSCO). Cells were maintained at $37{ }^{\circ} \mathrm{C}$ in a humidified $5 \% \mathrm{CO}_{2} / 95 \%$ air atmosphere in Dulbecco's modified Eagle's medium (DMEM) (SigmaAldrich, D6429) supplemented with $10 \%$ foetal bovine serum (Sigma-Aldrich, 0804 ) and $1 \%$ penicillin-streptomycin.

\subsubsection{Investigation of cell adhesive quality of surfaces}

In order to determine if the cells had a preference for either the machined ground or the unprocessed surfaces, an adhesion assay was carried out using the MTT assay. First, polyurethane casts (6-mm diameter) were cut using a Biopunch (SLS) and placed in the wells of a 96-well plate. The polymer discs were then sterilised with UV light for $30 \mathrm{~min}$. Cells were seeded onto the surfaces at a cell density of 10,000 cells per well. The cells were left to incubate for $2 \mathrm{~h}\left(37^{\circ} \mathrm{C} 5 \% \mathrm{CO}_{2}\right)$, after which the growth medium was removed and the polymer discs were washed with PBS $(\times 3)$. Next, the MTT assay was carried out to determine cell number. Briefly, MTT ( $5 \mathrm{mg} / \mathrm{ml}$ in DMEM) was added to each well and subsequently left to incubate for $3 \mathrm{~h}$ at $37{ }^{\circ} \mathrm{C}$ in a humidified $5 \% \mathrm{CO}_{2} / 95 \%$ air atmosphere. Next, the medium was removed and replaced with DMSO in order to dissolve the formazan crystals. The plate was then read at $570 \mathrm{~nm}$ using a 96-well plate reader with absorbance indicating the relative number of cells.

\subsubsection{Investigation of cell proliferative quality of surfaces}

In order to determine if the surfaces promoted cell viability, a proliferation assay was carried out using the MTT assay. Polyurethane casts (6-mm diameter) were prepared and sterilised as described above (Sect. 2.2.2). Cells were seeded at a density of 10,000 cells per well and left to incubate for 24, 48 or $72 \mathrm{~h}\left(37^{\circ} \mathrm{C} 5 \% \mathrm{CO}_{2}\right)$. At each time point $(24,48,74 \mathrm{~h})$, an MTT assay was carried out as described above, in order to determine absorbance and relative cell number.

\subsubsection{Investigation of cell migration properties of surfaces}

To determine if the ground patterned surfaces affected cell migration, time-lapse imaging and subsequent cell tracking were preformed over a 4-h period using a Zeiss LSM 510 confocal microscope. Briefly, polymer surfaces were washed in ethanol, for sterilisation purposes, and then were washed in PBS to remove traces of ethanol, before being placed into a 
35-mm cell culture dishes. Next, 200,000 cells $/ \mathrm{cm}^{2}$ were seeded on to polymer surfaces and the dish was placed into the microscope environmental chamber ( $\mathrm{S}-2$, PeCon $\mathrm{GmbH}$, Germany). The chamber was maintained at $37^{\circ} \mathrm{C}$ and $5 \%$ $\mathrm{CO}_{2}$ in a $60-70 \%$ humidified air atmosphere using a by Temcontrol 37-2 and CTI-controller 3700 (PeCon GmbH, Germany). Images were taken every $15 \mathrm{~min}$ for $4 \mathrm{~h}$ using a $\times 20$ Plan-Apo/0.75 NA DIC objective lens, while scanning using a Helium-Neon $(\mathrm{HeNe})$ laser at $543 \mathrm{~nm}$. ImageJ software (National Institute of Health, NIH) with manual tracking plugin (Institute Curie, France) was used to analyse the data produced from the time-lapse image series.

\section{Results}

\subsection{Surface patterning}

Surface patterns were created on the stainless steel moulds via a single pass across the samples by the dressed wheel at the different wheel depths to generate a 'ploughed field' feature effect as is seen in Fig. 1. The different surface patterns were designated M1, M2, M3 and M4 for the 2-, 4-, 6- and 10- $\mu \mathrm{m}$ wheel dressing depth, respectively. The profiles show a pattern of peaks and troughs across the surface that varies in height. The width of the features also varies which results in channels that run along the surface that are not identical across each surface or across the different surfaces as can be seen in Fig. 2. The stainless steel moulds were then used to produce a polymer cast which were designated $\mathrm{P} 1, \mathrm{P} 2, \mathrm{P} 3$ and $\mathrm{P} 4$, being identifiable with respect to their corresponding metal counterparts.

\subsection{Surface characterisation of ground surfaces}

To compare the different ground surfaces to each other and their 'inverse' polymer casts, the surfaces were imaged using a white light interferometer microscope. This allowed for surface height measurements to be obtained. As can be seen from Fig. 3, there is an increase in the height of surface features as the dressing depth increases. When comparing this result to the polymer cast, this trend is also seen; however, a decrease can be seen in terms of the surface heights through a direct comparison. There is a discrepancy between the M1 and P1 surfaces where this drop in surface height is not seen (Figs. 3 and 4).

Further analysis was performed on the surfaces through the white light interference microscope in order to determine parameters such as the average surface roughness $(\mathrm{Ra})$, the average maximum height value (Rt) and mean roughness depth (Rz) values of the ground surfaces (Table 1). The average Ra values for the ground metal surfaces were found to be 0.748 , $0.744,0.876$ and 1.36 , respectively. The average Rz values for the metal casts were 5.81, 5.76, 6.76 and 8.14 for the same respective surfaces. For the Rt, average maximum height values, these were found to be 6.47, 6.28, 8.02 and 9.54, respectively. Table 1 shows that there is a correlation between the increase in surface feature height and an increase in values of Ra, Rt and Rz. There is a small drop in the values between
Fig. 1 White light interferometer microscope images. All images were taken at $\times 25$ magnification
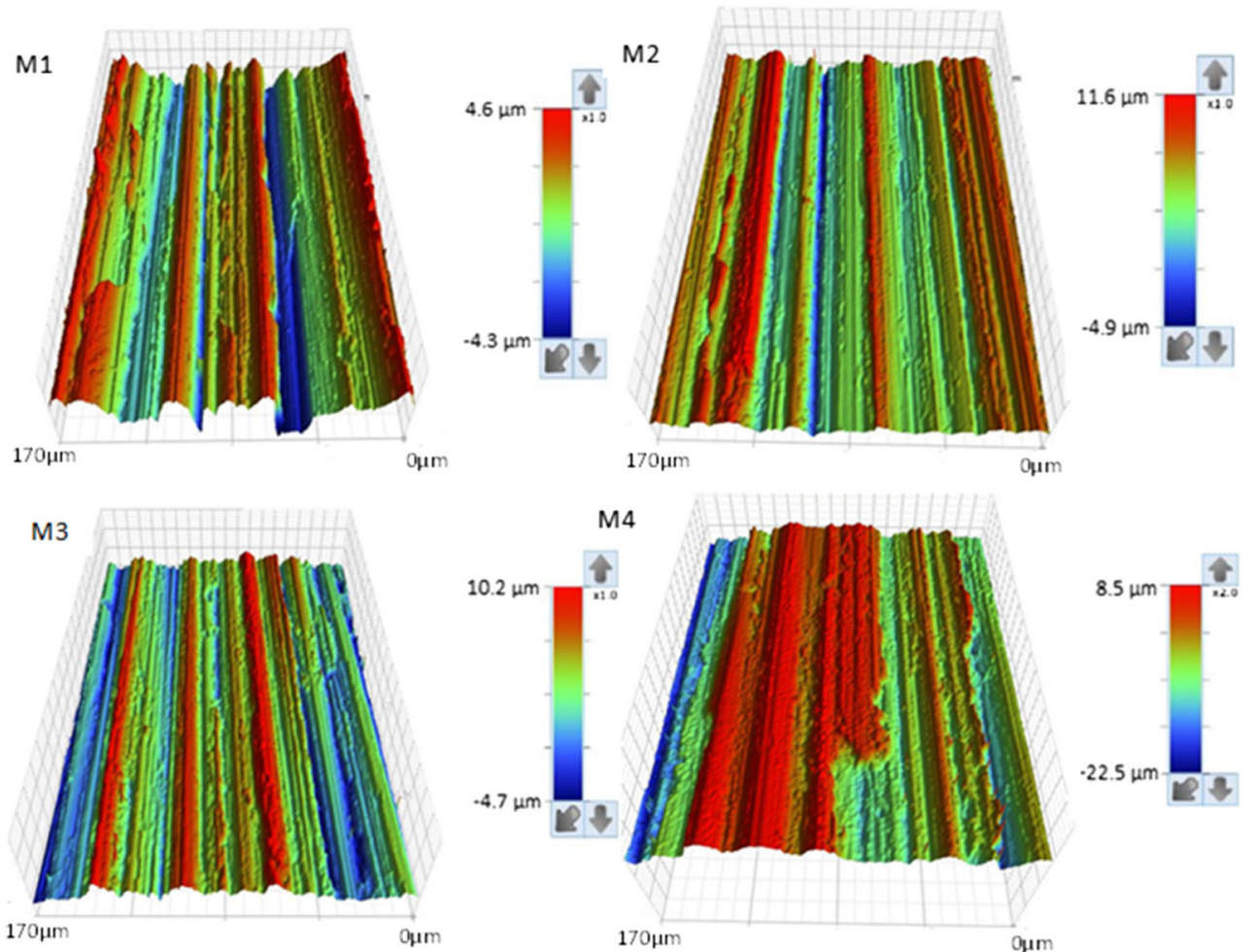

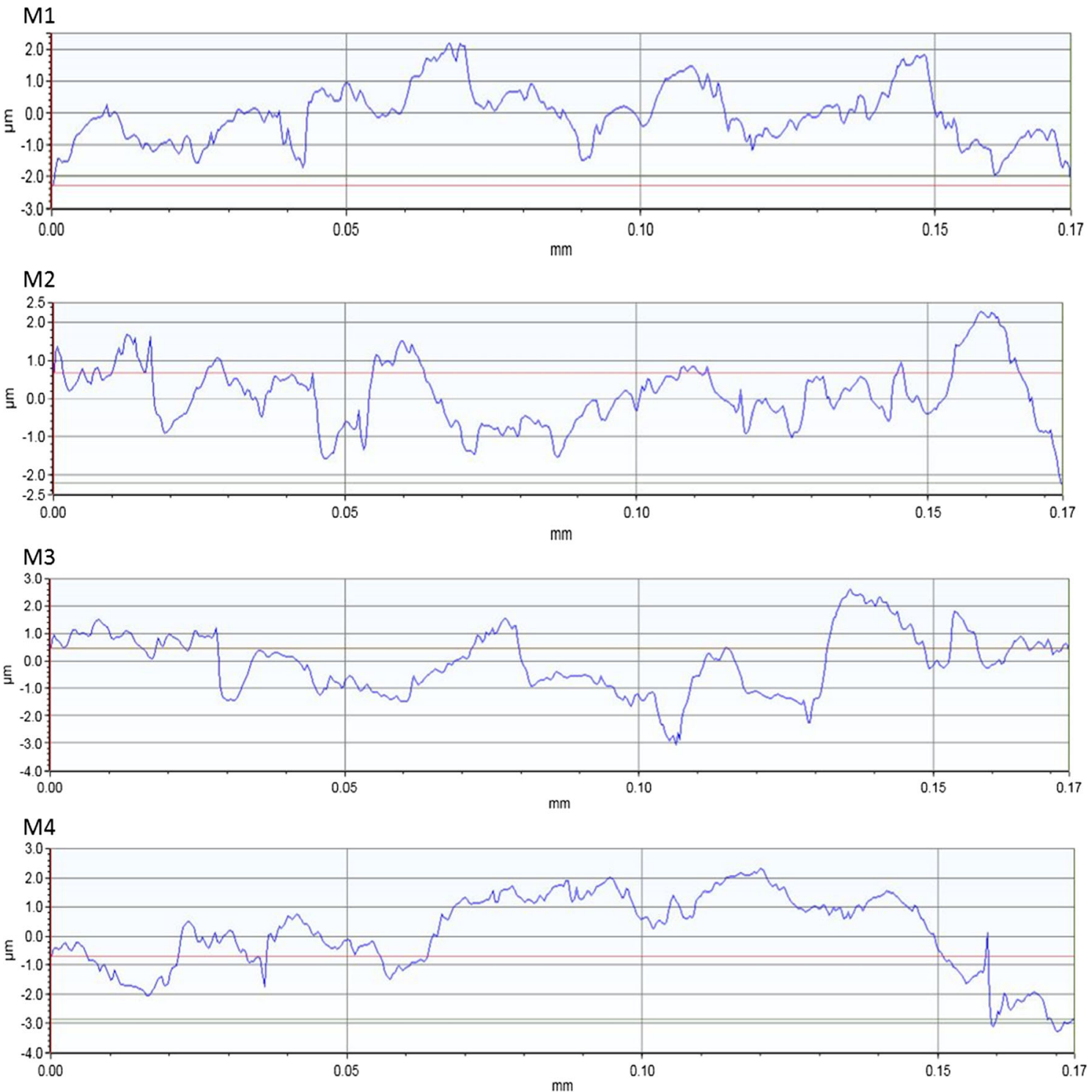

Fig. 2 White light interferometer microscope surface profiles. All images were taken at $\times 25$ magnification

surfaces M1 and M2, where the wheel depth was 2 and $4 \mu \mathrm{m}$, respectively, but as the feature height increased to 6 and $10 \mu \mathrm{m}$, the values for Ra, Rt and Rz also increased, resulting in a positive trend between surface height and the analysis values.

Surface analysis was also performed on the inverse polymer casts, and the Ra, Rt and Rz values can be seen in Table 1 . It can be seen that, in a similar fashion to the stainless steel moulds, the values show a trend to increase from the lowest feature height value to the largest. However, Table 1 also shows that for casts $\mathrm{P} 2$ and $\mathrm{P} 3$, the mean feature height values are lower compared to $\mathrm{P} 1$ but still show an increase in mean height through to P4. This is not seen for the metal moulds (Figs. 3 and 4) which also do not show such high values for the Rt and Rz analysis, suggesting that this discrepancy may be as a result of the casting processes, where possibly the liquid polymer is not filling the mould accurately, hence resulting in this difference in values.

\subsection{Cell behaviour}

\subsubsection{Cell adhesion}

In order to determine how the different machine ground surfaces affected cell adhesion, a MTT adhesion assay was performed $2 \mathrm{~h}$ after the cells were seeded on to the surfaces. Figure 5 shows that there is a clear difference between the adhesions of the cells to the unprocessed polymer compared to the ground surfaces. The results show that on the unprocessed polymer, less cells had adhered to the surface after $2 \mathrm{~h}$ compared to all of the processed surfaces. There is also an observable difference between the different machine ground 
Fig. 3 Mean feature height of ground metal samples.

Measurements achieved via surface profiles taken by white light interferometer at $\times 50$

magnification. $N=104,64$ and

93. Error bars represent standard error of the mean

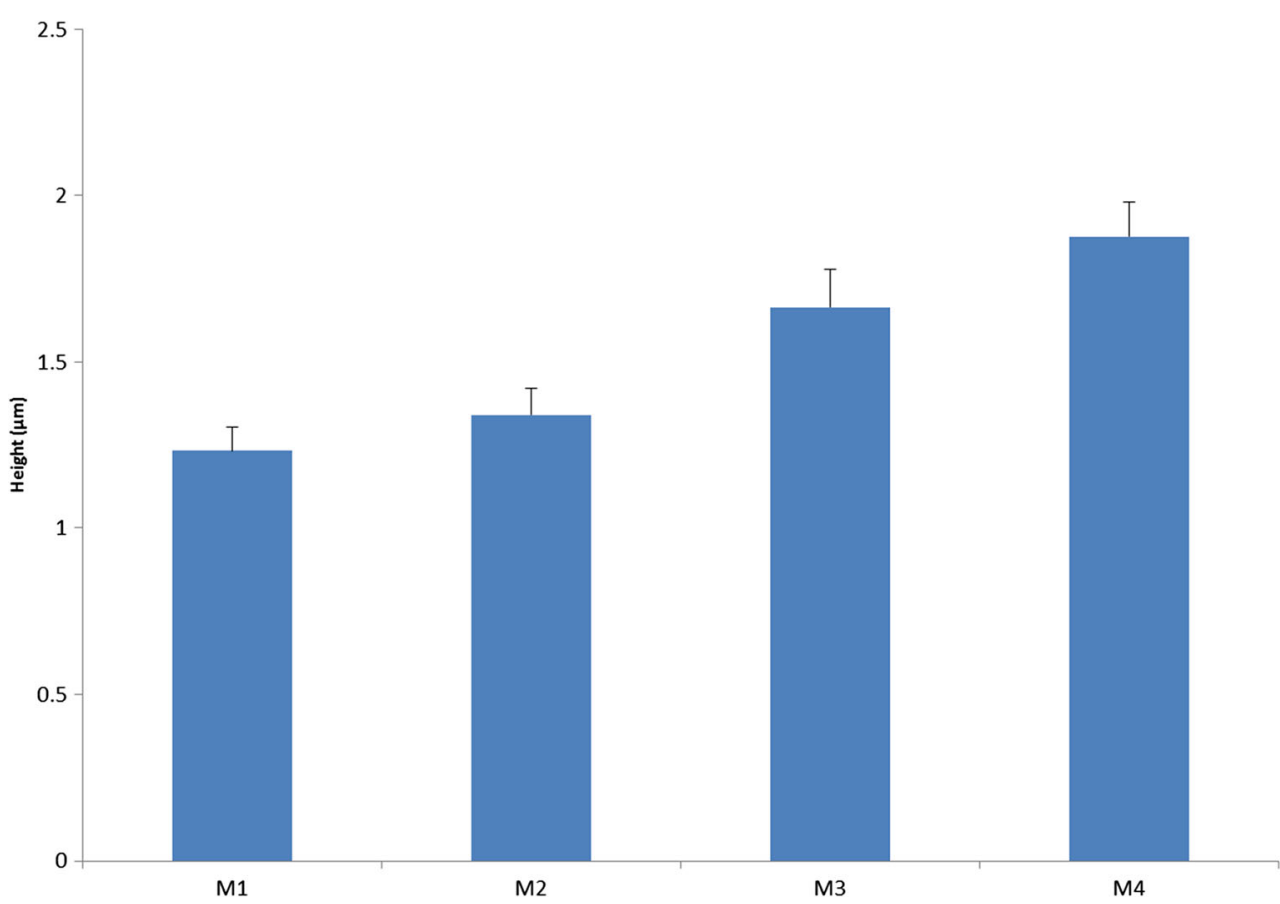

surfaces where we see an increase in cell adhesion as depth of cut increases up until surface P3 (Fig. 5).

\subsubsection{Cell proliferation}

In order to compare the effects of the various different surfaces upon cell proliferation, an MTT test was performed after 24, 48 and 72 h. Figure 6 shows that after 24, 48 and 72 h, cells were found to proliferate steadily on the unprocessed surface, as indicated by the increase of the absorbance values. This trend was also observed with surface P4, although the cell proliferation rate was much lower compared to the unprocessed sample. In contrast, cells did not seem to proliferate on surfaces $\mathrm{P} 1$ and $\mathrm{P} 2$, as cell number remained relatively steady over time on these surfaces, while surface P3 was only found to promote proliferation after $72 \mathrm{~h}$. These results
Fig. 4 Average height of inverse polymer casts of metal moulds. Measurements taken via white light interferometer. $N=125,140$, 162 and 107. Error bars represent standard error of the mean

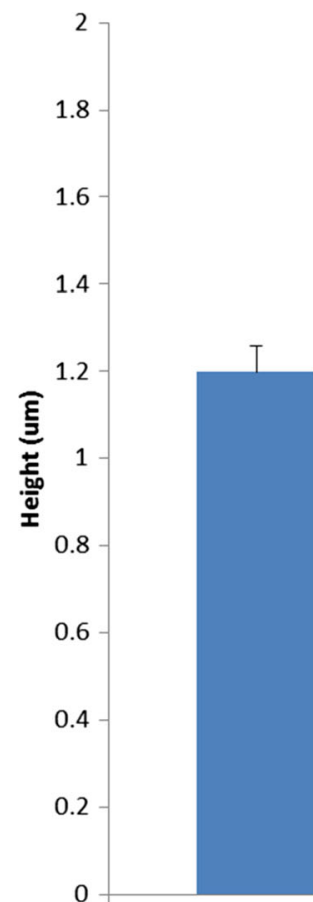

P1

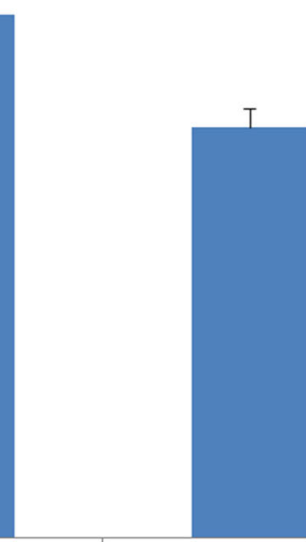

P2

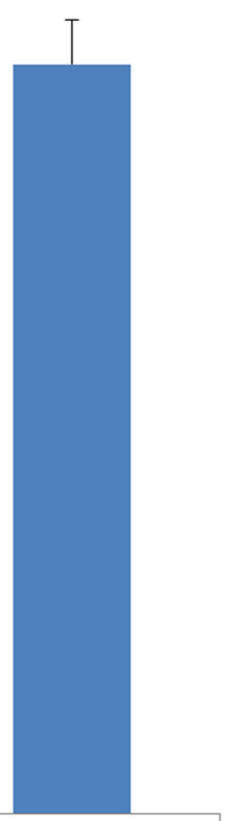

P4 
Table 1 Mean height, Ra, Rt and Rz measurements for metal moulds and polymer casts taken via white light interferometer

\begin{tabular}{|c|c|c|c|c|c|c|c|c|}
\hline \multirow[t]{2}{*}{ Surface } & \multirow[t]{2}{*}{$\begin{array}{l}\text { Depth of } \\
\text { cut }(\mu \mathrm{m})\end{array}$} & \multicolumn{4}{|c|}{ Surface analysis } & \multicolumn{3}{|c|}{$\begin{array}{l}\text { Standard error of the } \\
\text { mean }\end{array}$} \\
\hline & & $\begin{array}{l}\text { Mean } \\
\text { height }\end{array}$ & $\mathrm{Ra}$ & Rt & $\mathrm{Rz}$ & $\mathrm{Ra}$ & Rt & $\mathrm{Rz}$ \\
\hline M1 & 2 & 1.23 & 0.75 & 6.47 & 5.81 & 0.086 & 0.782 & 0.575 \\
\hline M2 & 4 & 1.34 & 0.74 & 6.28 & 5.76 & 0.043 & 0.782 & 0.132 \\
\hline M3 & 6 & 1.66 & 0.88 & 8.02 & 6.76 & 0.034 & 1.07 & 0.421 \\
\hline M4 & 10 & 1.88 & 1.36 & 9.54 & 8.14 & 0.163 & 0.862 & 0.741 \\
\hline P1 & 2 & 1.20 & 0.85 & 17.22 & 12.26 & 0.047 & 4.28 & 2.16 \\
\hline $\mathrm{P} 2$ & 4 & 0.94 & 0.82 & 11.22 & 8.10 & 0.095 & 1.09 & 0.632 \\
\hline P3 & 6 & 1.15 & 0.78 & 11.76 & 8.87 & 0.068 & 1.47 & 0.879 \\
\hline P4 & 10 & 1.72 & 1.34 & 28.64 & 23.30 & 0.047 & 5.68 & 2.9 \\
\hline
\end{tabular}

For all values, $=5$. All values are in microns

indicate that the manipulation of surface features, their size and distribution, generated through machine grinding, can be used to control the proliferation rate of fibroblast cells.

\subsubsection{Cell migration}

To compare the effect of machine ground surfaces on cell migration, fibroblast cells were seeded onto the surfaces and left to attach for $2 \mathrm{~h}$, before being imaged every $15 \mathrm{~min}$ for $4 \mathrm{~h}$. This allowed us to track cell movement over time. The distance moved was determined through the sum total of the distance moved by each cell after $4 \mathrm{~h}$. Figure 7 shows that cells on surfaces $\mathrm{P} 2$ and $\mathrm{P} 3$ moved considerably further when compared to the other surfaces, moving a distance of around 4900 and $4200 \mu \mathrm{m}$, respectively. The unprocessed surface, surface P1 and surface P4 showed similar distances moved after the 4-h period, but these were all under $3000 \mu \mathrm{m}$, showing a significant reduction in distance moved compared to P2 and $\mathrm{P} 3$.

\section{Discussion}

This work highlights the ability of material grinding to be utilised as a method for developing functional surfaces for biomedical applications. Through dressing the grinding wheel, a material depth of cut varying between 2 and $5 \mu \mathrm{m}$ produced surfaces having a mean feature height of between 1.2 and $1.9 \mu \mathrm{m}$, which rivals other more advanced methods. The process was designed to produce features in a ploughed field pattern which is seen on all surfaces (Fig. 1). However, the features are not universal on each surface, with variations in feature width and height seen across all surfaces (Fig. 3). This is not a problem in its self, due to the randomness of the naturally occurring extracellular matrix that we are attempting to mimic here, a protein scaffold that cells attach to within tissues. Surface analysis values were determined, specifically $\mathrm{Ra}$, Rt and Rz, which showed an increase from the smallest wheel depth to the largest, as would be expected. However, between M1 and M2, the smaller wheel depth surfaces ( 2 and
Fig. 5 Surfaces were seeded with $\sim 10,000$ cells and left for $2 \mathrm{~h}$ to attach. An MTT assay was carried out to determine how many cells had attached to the surface. Error bars represent standard error of the mean

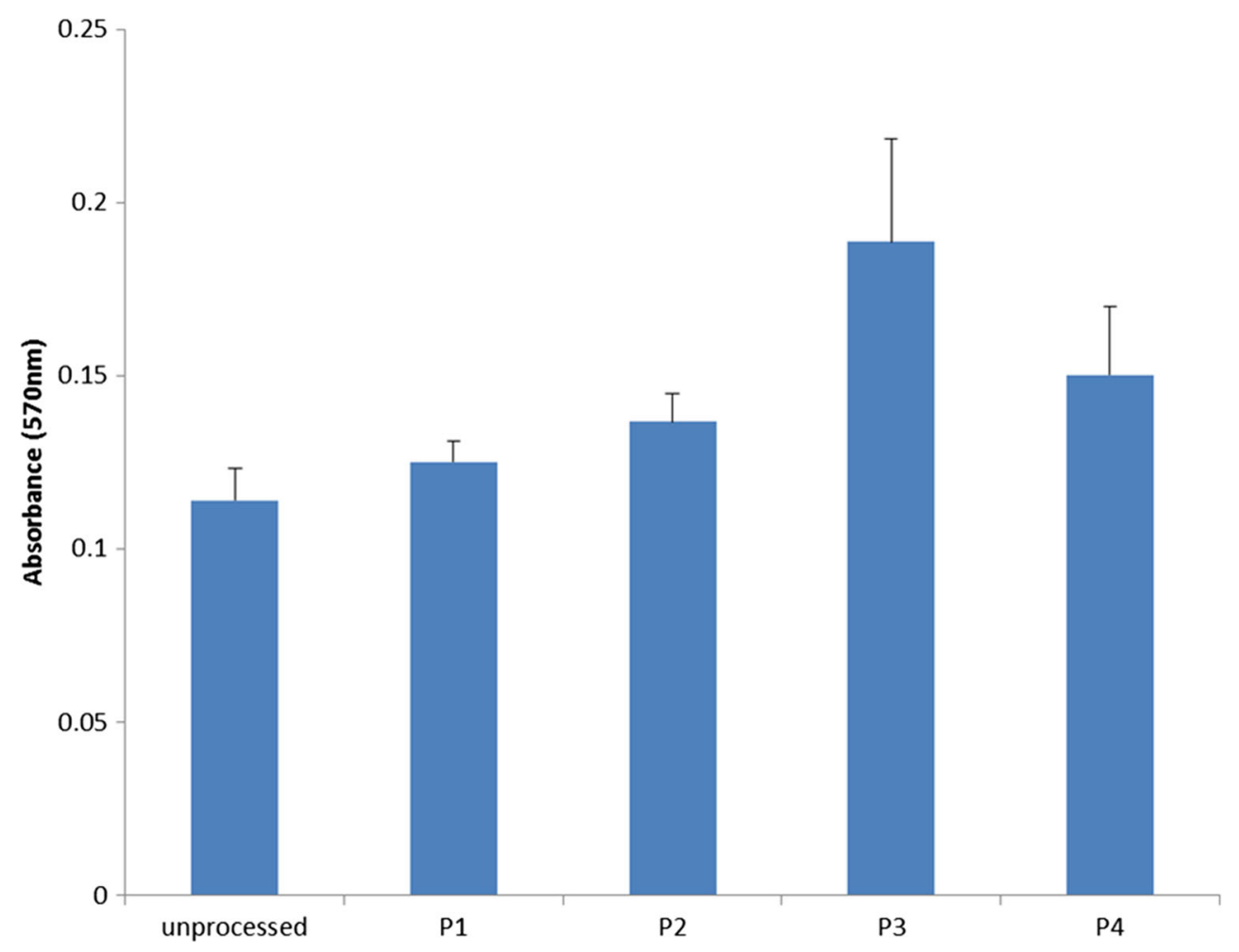


Fig. 6 Surfaces were seeded with $\sim 10,000$ cells and left for 24,48 and $72 \mathrm{~h}$. An MTT assay was carried out to determine how many cells had attached to the surface. Error bars represent standard error of the mean

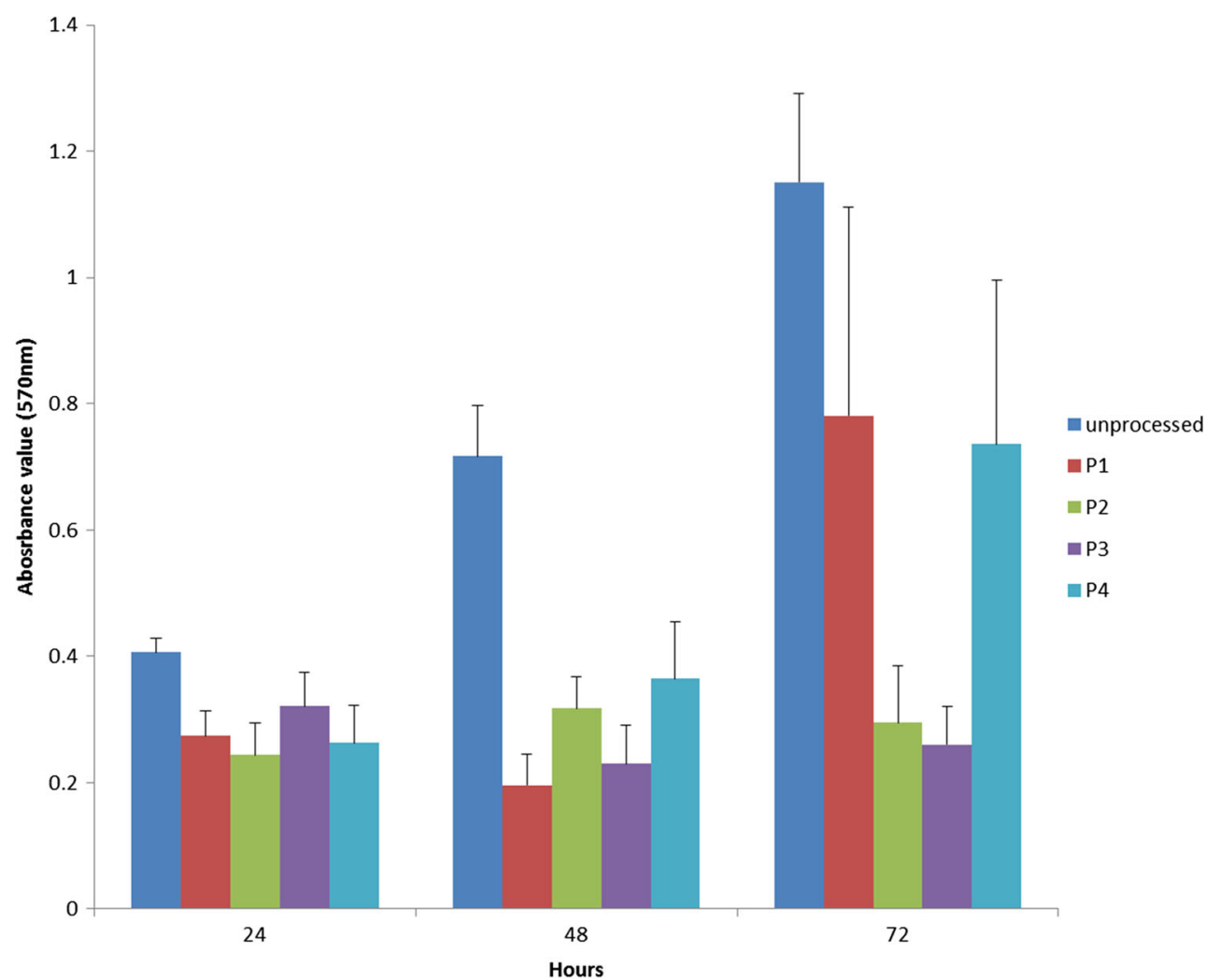

$4 \mu \mathrm{m}$, respectively), there is a drop in each of these surface parameters before the values increase through M3 and M4.

The casting process produced polymer surfaces of similar features, though not identical in dimensions. There was a discrepancy in the trend of an increase in mean feature height at the 4- $\mu \mathrm{m}$ wheel depth (P2). A drop in feature height is seen here suggesting an inaccuracy in the casting process which may be due to the viscosity of the polymer, i.e. too viscous to flow into and settle between the smallest features.
Fig. 7 The total distance moved in microns by 30 cells over $4 \mathrm{~h}$ $(* n=27)$. Error bars represent standard deviation

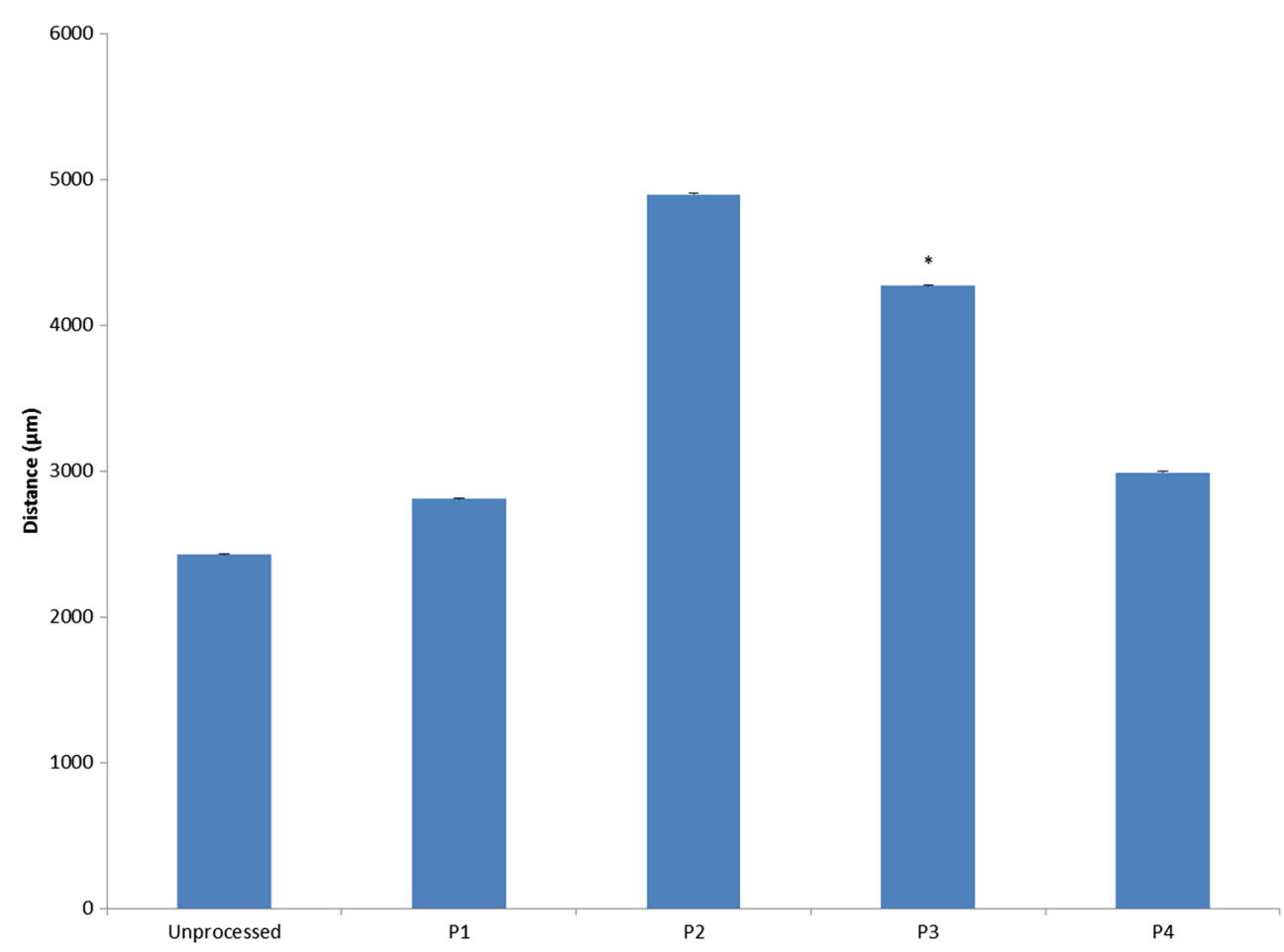


When analysing the effects of surface topography on cell adhesion, there is a clear difference between the un-patterned surface and the machine ground surfaces. The effect of surface topography on cell adhesion is linked to an effect known as 'contact guidance', where cells are able to sense their immediate environment and react to it [9]. This is seen with the ground polymer surfaces which show an increased level of adhesion when compared to the unprocessed polymer, hence suggesting a link between the surface features and the cells ability to adhere to the surface. The P3 surface shows a higher level of cell adhesion than the other ground surfaces, and this may be linked to the surface analysis results in which P3 has low values for Ra, Rt and $\mathrm{Rz}$ (Table 1). This finding links to other work which shows that increases in surface roughness can have a negative impact on fibroblast cell adhesion and may potentially prevent initial adaption of the cells to surface [21]. This effect is possibly linked to the number of focal adhesion contacts being formed between the cell and the surface as Grossner-Schreiber et al. had previously shown that there were an increased number of focal adhesion contacts on surfaces with a lower Ra value [14]. However, this is not seen for the unprocessed polymer, which shows a lower level of adhesion and also shows much lower surface analysis values. These results suggest that cells are able to attach to the machine ground surface much more quickly than is the case for the unprocessed polymer surface, as the MTT test was performed after a duration of only $2 \mathrm{~h}$. If this attachment time was increased, a similar attachment level may be seen. The effect of surface topography on cell behaviour has been shown previously, with cell alignment shown when cells are seeded onto grooved surfaces $[10,19]$ as well as when being seeded onto highly ordered nanopits that effect cytoskeleton organisation [2]. Fibroblasts, in particular, have been shown to adhere with more affinity, when exhibiting a well-spread, flattened morphology (i.e. on a flat surface) [4]. Results have also been shown where surface topography has a negative impact on fibroblast cell adhesion [5, 24].

When analysing the effects of surface topography on cell proliferation, there is also a difference between the responses of cells grown on the unprocessed polymers, compared with those grown on the machine ground surfaces. The unprocessed polymer promotes cell growth to a greater extent when compared to the other surfaces at the 24- and 48-h time points. These results support previous research that shows that increased surface roughness impaired fibroblast cell growth [12]. They can also be linked to previous research showing similarities in that fibroblast cells that were seeded onto patterned surfaces resulted in the downregulation of transcription factors and genes involved with proliferation, while also being linked to a decrease in cell spreading [8]. However, there is no significant difference between the machine ground surfaces when comparing at the same time points. After $72 \mathrm{~h}$, the P1 and P2 surfaces show an increased level of cell growth, suggesting that the cells growing on those surfaces have been able to settle and begin spreading on the surface, hence promoting the process of proliferation. When comparing the cell number across the three discrete time duration points, there is no significant difference for surfaces $\mathrm{P} 2$ and $\mathrm{P} 3$, suggesting limited to no cell proliferation on these surfaces. That the unprocessed polymer and P1 seem to promote cell growth to a greater extent may be due to the smaller size of their features, as previous research has shown that cells prefer smaller features over larger regarding proliferation. Kolind et al. showed that fibroblasts exhibit improved proliferation on pits with smaller gap sizes (ones that they could cover easily) when compared to pits with larger gap sizes [17].

When comparing the ability of the cells to migrate on the surfaces, it was found that all machine ground surfaces enhanced cell migration when compared to the unprocessed surface. These results mirror the adhesion studies, where the surfaces that showed enhanced adhesion also seem to promote greater cell migration across the surface. When comparing these results to the surface analysis values, it could be suggested that the surfaces with lower values for $\mathrm{Ra}$, Rt and $\mathrm{Rz}$ and feature height promote cell adhesion and migration. However, this is not seen for surface P4, which despite showing the largest values for the surface analysis shows a more enhanced level of cell migration and adhesion when compared to surface P1. The effect of surface features on cell migration has been seen before; Clark et al. showed that when cells encountered topological steps, as the height of the step increased, there was a significantly decreased crossing frequency, with more cells turning back rather than climbing up the substrate surface feature [3]. The effect of substrate surface features on cell migration can also be seen in the work by Hamilton et al., where fibroblast cells were seen to hug groove walls in order to turn their entire body around corners [15].

This work demonstrates that grinding technology can be used as an alternative, cost-effective method to generate functional surfaces that can be used to control aspects of fibroblast cell behaviour. However, further work would be required to fully understand the effect of surface roughness and pattern geometry on cell behaviour and improve the process through empirical determination of the optimal grinding parameters required to enhance the quality, resolution and organisation of the surface features.

Open Access This article is distributed under the terms of the Creative Commons Attribution 4.0 International License (http:// creativecommons.org/licenses/by/4.0/), which permits unrestricted use, distribution, and reproduction in any medium, provided you give appropriate credit to the original author(s) and the source, provide a link to the Creative Commons license, and indicate if changes were made. 


\section{References}

1. Biela SA, Su Y, Spatz JP et al (2009) Different sensitivity of human endothelial cells, smooth muscle cells and fibroblasts to topography in the nano-micro range. Acta Biomater 5:2460-2466

2. Biggs MJP, Richards RG, Gadegaard N et al (2007) Regulation of implant surface cell adhesion: characterization and quantification of S-phase primary osteoblast adhesions on biomimetic nanoscale substrates. J Orthop Res 25:273-282

3. Clark P, Connolly P, Curtis AS et al (1987) Topographical control of cell behaviour. I Simple step cues. Development 99:439-448

4. Couchman JR, Hook M, Rees DA et al (1983) Adhesion, growth, and matrix production by fibroblasts on laminin substrates. J Cell Biol 96:177-183

5. Curtis ASG, Casey B, Gallagher JO et al (2001) Substratum nanotopography and the adhesion of biological cells. Are symmetry or regularity of nanotopography important? Biophys Chem 94: 275-283

6. D'arcangelo E, Mcguigan AP (2015) Micropatterning strategies to engineer controlled cell and tissue architecture in vitro. Biotechniques 58:13-23

7. Dalby MJ, Mccloy D, Robertson M et al (2006) Osteoprogenitor response to semi-ordered and random nanotopographies. Biomaterials 27:2980-2987

8. Dalby MJ, Riehle MO, Sutherland DS et al (2005) Morphological and microarray analysis of human fibroblasts cultured on nanocolumns produced by colloidal lithography. Eur Cell Mater 9:1-8, discussion 8

9. Dalby MJ, Riehle MO, Yarwood SJ et al (2003) Nucleus alignment and cell signaling in fibroblasts: response to a micro-grooved topography. Exp Cell Res 284:274-282

10. Duncan AC, Rouais F, Lazare S et al (2007) Effect of laser modified surface microtopochemistry on endothelial cell growth. Colloid Surf B 54:150-159

11. Frey MT, Tsai IY, Russell TP et al (2006) Cellular responses to substrate topography: role of myosin II and focal adhesion kinase. Biophys J 90:3774-3782

12. Gomez-Florit M, Xing R, Ramis JM et al (2014) Human gingival fibroblasts function is stimulated on machined hydrided titanium zirconium dental implants. J Dent 42:30-38
13. Gray C, Boyde A, Jones SJ (1996) Topographically induced bone formation in vitro: implications for bone implants and bone grafts. Bone 18:115-123

14. Grossner-Schreiber B, Herzog M, Hedderich J et al (2006) Focal adhesion contact formation by fibroblasts cultured on surfacemodified dental implants: an in vitro study. Clin Oral Implants Res 17:736-745

15. Hamilton DW, Oakley C, Jaeger NA et al (2009) Directional change produced by perpendicularly-oriented microgrooves is microtubule-dependent for fibroblasts and epithelium. Cell Motil Cytoskeleton 66:260-271

16. Harriott LR (2001) Limits of lithography. Proc IEEE 89:366-374

17. Kolind K, Dolatshahi-Pirouz A, Lovmand J et al (2010) A combinatorial screening of human fibroblast responses on microstructured surfaces. Biomaterials 31:9182-9191

18. Le Guehennec L, Soueidan A, Layrolle P et al (2007) Surface treatments of titanium dental implants for rapid osseointegration. Dent Mater 23:844-854

19. Leclerc A, Tremblay D, Hadjiantoniou S et al (2013) Three dimensional spatial separation of cells in response to microtopography. Biomaterials 34:8097-8104

20. Matsuzaka K, Yoshinari M, Shimono M et al (2004) Effects of multigrooved surfaces on osteoblast-like cells in vitro: scanning electron microscopic observation and mRNA expression of osteopontin and osteocalcin. J Biomed Mater Res A 68:227-234

21. Mustafa K, Silva Lopez B, Hultenby K et al (1998) Attachment and proliferation of human oral fibroblasts to titanium surfaces blasted with $\mathrm{TiO} 2$ particles. A scanning electron microscopic and histomorphometric analysis. Clin Oral Implants Res 9:195-207

22. Shen X, Ma P, Hu Y et al (2015) Mesenchymal stem cell growth behavior on micro/nano hierarchical surfaces of titanium substrates. Colloids Surf B Biointerfaces 127:221-232

23. Voisin M, Ball M, O'connell C et al (2010) Osteoblasts response to microstructured and nanostructured polyimide film, processed by the use of silica bead microlenses. Nanomed-Nanotechnol 6:35-43

24. Walboomers XF, Ginsel LA, Jansen JA (2000) Early spreading events of fibroblasts on microgrooved substrates. J Biomed Mater Res 51:529-534 